\title{
ANALYSIS AND MODELS FOR THE REDUCTION OF FOOD WASTE IN ORGANIZED LARGE-SCALE RETAIL DISTRIBUTION IN EASTERN SICILY
}

\author{
Maurizio Lanfranchi, Carlo Giannetto and Angelina De Pascale \\ Department of Economics, Business, Environmental and Quantitative Methods, \\ University of Messina, Messina, Italy
}

Received 2014-10-08; Revised 2014-11-19; Accepted 2014-11-20

\begin{abstract}
Nowadays, food waste is one of the main global paradoxes and raises profound questions from the social point of view. The causes of food losses and food waste are varied and differ according to the various stages of the food chain. The problem of food waste prompted the European Parliament to proclaim 2014 the "European year against food waste" and to adopt a resolution which should lead to a reduction of $50 \%$ of waste by the year 2025 . This study proposes the possible corrective actions, to be taken at the level of retail distribution and facing the end customer, to achieve the goal reducing of food waste (Fiore et al., 2008). The research was conducted by a group of scholars of the Department of Economics, Business, Environmental and Quantitative Methods, at the University of Messina, on a sample area of eastern Sicily. In particular thirteen retail outlets were analyzed by collecting and processing data on sales, broken down by sector, for the period 2009 to 2013 . The research conducted has shown that the food sector that contributes most to food waste, in the area investigated, is that of fruit and vegetables, the study has provided a detailed analysis of the ten most wasted foods. The work finally comes to processes that involve many different scenarios for reducing waste, encouraging a comparison, of the products most wasted, by providing potential solutions or corrective actions aimed at reducing the phenomenon analyzed.
\end{abstract}

Keywords: Food Waste, Food Losses, Food Wastage, Food Supply Chain, Negative Externalities

\section{INTRODUCTION}

The concept of food waste is not based on a single definition or existence of uniform methods to calculate it. The studies carried out so far on the waste data are incomplete and often inadequate or even contradictory. Consequently to analyze and quantify the occurrence of losses and food waste is a far from simple task. Of course food is wasted at every stage of the food chain from the moment of its production to its sale to reach the stage of domestic consumption (Lanfranchi, 2012). Most research to date has focused on the formation of waste Corresponding Author:Maurizio Lanfranchi, Department of University of Messina, Messina, Italy during production and global distribution, showing how the waste appears, most of the time, inevitable: Much of which is cannot be eaten or waste resulting from incorrect inventory management, overproduction, altered or damaged products (Graham-Rowe et al., 2014). Looking at consumption, however, if it is true that waste was born in the $50 \mathrm{~s}$, it is necessary to recall the changes in the lifestyle of consumers, attributable surely to socioeconomic variables, but also to cultural variables (D'Silva et al., 2010). The first, related not only to the demographic changes, to the general conditions of consumption determined by rapid urbanization, the Economics, Business, Environmental and Quantitative Methods, 
increased general well-being with the increase in "per capita" income, the spread of industrial food chains, the mass use of electrical appliances, which allow consumers to buy and store large amounts of food, as well as changes in the organization of work, in particular the extension of nationalized labour wage and working hours, as well as the lack of responsibility of the role of women in relation to food, which has resulted in the reallocation of the phases of the process of food consumption among the members of the family (Bernstad, 2014). Among the variables related to the socio-cultural sphere we can mention the new and different eating habits (Di Trapani et al., 2014). On one hand, the change in the composition of the diet, due to the increase in disposable income and, on the other hand, the increasing resorting to fast food, takeaways, convenience and ready food (D’Amico et al., 2014). The reduced quantity and quality of time spent on eating means that the meals are had in a hasty fashion and the food, always available and at all hours, is taken for granted.

\subsection{Food Waste Problem of the XXI Century: Ethical, Economic and Environmental Aspects}

In the twenty-first century almost half of the food produced worldwide, equivalent to about two million tons, is not consumed, but thrown away, without any attempt to recover any of it through appropriate actions of recycling or reuse. You only need to read the various reports by the ONU, FAO, IME and other bodies to realize the gravity of the situation. The data emerging from the alarming report made by IME (Institution of Mechanical Engineers British Agency) showed that, among the factors of waste, expiration dates indicated on the food which are too close, together with backward agricultural practices and techniques, are among the causes of greater responsibility in determining unnecessary and burdensome surplus food (Tudisca et al., 2013). In fact, studies conducted in the field summarize this current alarming situation in the world. The level of severity is such that the deaths on our planet were 29 million, due to excess food and those due to the lack of food are 36 million. This situation has led to the exasperation of the production destined to feed herds of animals, to the point that about one third of global production is intended for the nutrition of about 3 million heads of livestock. A similar situation is represented by the world's water needs for livestock, which, according to reliable estimates, in 2050 is expected to be around 45 billion $\mathrm{m}^{3}$ of water. To complicate the situation considerably, according to IME, are the diets of meat, considered that the exploitation of water resources for farming is much higher than agricultural crops (for a pound of meat the amount of water needed is about 2050 times higher than the water requirement of crop production) (Garnsworthy, 2012). Food waste that is determined along the retail distribution channel is assuming frightening proportions at international level; Italy contributes to this needless waste of natural resources, with obvious negative impacts on the environment, with an estimated amount of about 265 thousand tons of product. A substantial part of this product becomes an inconvenient waste and expensive to dispose of (Levis et al., 2010).

Several studies also show that waste in consumption has become, in the course of time, a worrying quantity (Pradhan et al., 2014). In Italy the annual waste from agriculture is approximately $16 \%$, that of milk, dairy products, eggs and meat is $35 \%$. From here the studies on the economic impact of waste have led, through various interpretations, to establish that in our country annually about 10 billion Euros in food goes to waste, while the same food products wasted could feed a population, in quantitative terms, almost equivalent to that of Italy (Kim et al., 2014). The waste must be considered as a failure of the management system of production and distribution, as the output has required numerous and costly inputs, but it has not found its natural outlet on the market through the action of purchase by the consumer (Mahdei et al., 2010). This failure, with the incalculable consequences which have been mentioned, resulted in another equally disturbing situation, which is linked to the health of the consumer, who, driven by marketing strategies and advertising, buys food in excess of his normal daily calorie needs, with the obvious result of adopting a dietary pattern, in the long run unbalanced and by contracting diseases, related to a diet not at all balanced, which causes among other complications obesity (Nahman and de Lange, 2013). According to estimates by IME, approximately $30-50 \%$ of the food does not even reach the plate of consumers, this in the light of a situation that, according to ONU statistics, foresaw a growing pressure on natural resources (Rentizelas et al., 2014). In fact, the predictions of population growth according to the $\mathrm{ONU}$ in the coming decades foresee, an increase of 3 billion people, with worrying problems of access to food. Precisely in view of this prediction and its alarming prospect, the IME invites everyone to combat the systematic waste of food. Tim Fox, head of energy to the environment at IME, said: The amount of food wasted 
and lost in the world is soaring (Sulaiman et al., 2012). This food could be used in the future to feed the world's population steadily increasing and to meet the needs of those suffering from hunger today. To talk about waste is not only to tackle the problem of disposing of products that are not consumed, but it is also to address issues related to environmental impact (Testa et al., 2014). The waste of natural resources consumed in fact, require unnecessary emissions of carbon dioxide released into the atmosphere that could have been avoided, in addition to issues related to the poor distribution of food in the world. Despite this alarming situation, in recent years attempts and strategies aimed, successfully, to mitigate the seriousness of the problem have been implemented. In particular the academic spin-off created by Prof. Segrè at the University of Bologna, who gave birth to Last Minute Market. Right from the studies to the creation of spin-off it shows that in Italy, in the agricultural sector only the waste due to the LSC, upstream of the production phase a waste of more than 70 million $\mathrm{m}^{3}$ of water is created, with a total consumption of resources of approximately 400 million $\mathrm{m}^{2}$. This production in excess of demand determines an emission into the atmosphere equivalent to about 8 million $\mathrm{kg}$ of carbon dioxide (Lo, 2009). Therefore, not surprisingly, the research team wanted to analyze, the vegetable sector, in an attempt to propose strategies to reduce waste in this area. This is combined with a progressive lengthening and increase in complexity of the food chain, mainly due to urbanization, to meet the food needs of a growing population, but also the rapid spread of the mass distribution Large Supermarket Chains (LSC) due to the increasing globalization of trade. To this end, there was the need to identify and separate, even within the same food chain, the different stages in which the differences are reflected, spelling out the meaning of the terms "loss", "waste" and "wastage".

Food loss is defined as the reduction of unintentional food for human consumption. This reduction is not intentional and stems from a number of inefficiencies along the food supply chain, such as the lack of infrastructures and logistics, lack of technology, skills or management skills (Lanfranchi et al., 2014a). The loss of food takes place primarily in the stages of production and post-harvest processing, that is, when the products remain on the field or when they are discarded during the processing steps, storage and transportation (Parfitt et al., 2010).

The term food waste, however, refers to the deliberate rejection of food (for human consumption) which is still perfectly edible. The difference, in this case, is due to the conduct by companies and individuals, especially by retailers and consumers (Giuseppe et al., 2014).

The expression food wastage, finally, indicates loss and waste together (Papargyropoulou et al., 2014).

\section{MATERIALS AND METHODS}

For the development of this section, different steps have been taken into account, in order to identify the aim of the research, select the target and the object, evaluate the quantity of waste/wastage in the selected stores (Er et al., 2011). To this end, a wide classification of observations, interviews, data elaboration on electronic sheets (Microsoft Excel) and data tables in MS Word, are used-over the years-to analyze this phenomenon.

\subsection{Aim of the Research}

The aim of the study, therefore materialized in the identification and analysis of wastage/waste within the complex food chain, in particular in large supermarket chains and to identify possible actions aimed at reducing the phenomenon, also in accordance with the provisions of the European Parliament Resolution of 2011 that plans to reduce waste by $50 \%$ by 2025 . To this end, in this study, the concept of "food loss" is identified as the difference in food linked to the product processed before being placed on the shelf for sale, identifying instead the "waste" only as an unsold product (Morley et al., 2014). The study aims to analyze the phenomenon in a land area fairly restricted by monitoring 13 large retail outlets located in the insular part of Southern Italy, in order to assess whether, in accordance with the existing literature which deals with the phenomenon on a global scale, the food waste is attributable to an incorrect management of a sale point or to socio-economic or cultural variables characterizing the purchasing behaviour of consumers, especially in the light of the socio-economic crisis that characterized the period considered (Crescimanno et al., 2014).

\subsection{Definition of the Context Analysis}

The analysis was conducted in the province of Messina through the selection and monitoring of 13 points of sale for a period of 5 years, from 2009 to 2013 . Through the methodology adopted a representative heterogeneous sample was formed of the different provinces: Inhabitants; area's topography (hills or coastal); economic vocation, whether farming was the main activity or not, in order to verify if the products were wasted-in the case of agriculture-they were substituted by local production, tourism (in order to 
assess the effect on the seasonality of waste) (Lanfranchi and Giannetto, 2014). The study has allowed us to select 9 municipalities and the retail outlets, reported in Table 1. The first consideration deals with the area of the outlets which, when compared with the resident population, is far superior and indicative of the fact that supermarkets analyzed span their sales also to neighbouring localities (Taleizadeh et al., 2009). From the observations carried out it has emerged that the local agricultural sector employs traditional systems characterized by simple technologies and by smallholders, including micro-enterprises engaged in subsistence agriculture or simply to meet the food needs of their families, with little integration in the local markets, with very limited or no access at all to foreign markets and with many non-local intermediaries servicing not only those outlets analyzed, but also the urban markets.

The area has then, especially in some of the locations examined, elements of specialization in tourism, in seaside tourism and therefore densely populated in the summer months.

\subsection{Methodology Adopted in the Research}

In order to evaluate the quantity of waste/wastage in stores analyzed and to identify whether the variables related to the socio-economic context analyzed, affect or not this phenomenon, or whether, instead, they are related to consumer behaviour and its power to purchase (also in the light of the economic crisis that characterized the period analyzed), a study was conducted, for every point of sale in order to identify:

- The impact of waste on the turnover in five years

- An examination of the sectors in order to identify the sectors that contributed the most to the waste, in quantitative terms and then in terms of economic loss (cost of goods supplied)

- Identification, of the sector which contributes most to waste, of the most important products in terms of rejection and subsequent identification of the waste and wastage (loss + waste), in order to perform a comparative study of the two phenomena and hypothesizing, finally policies to reduce rejection

The first step of the methodology has allowed us to verify the existence of food wastage and to quantify the impact on sales in the 13 outlets and throughout the period analyzed (Table 2), showing also how the phenomenon tends to affect the turnover during the period, to an increasing extent.

Subsequently, by examining the sectors that, during the period analyzed, showed the greatest amount of waste, the following sectors were analyzed:
- Sector 003-Delicatessen

- Sector 006-Poultry

- Sector 004-Dairy Products

- Sector 008-Butcher

- Sector 001-Food

- Sector 009-Fruit and Vegetables

- Sector 010-Frozen Foods

From the study carried out, leaving aside the areas which have recorded irrelevant values in terms of waste, the result is what is in Table 3.

However, for the sake of being thorough, it should be noted that for some areas such as "frozen foods" or "dairy", for difficulties attributable to reasons related to the packaging, it was not possible to deduce the relative weight in terms of $\mathrm{kg}$. But only the number of unsold pieces and its economic value in terms of loss (Sgroi et al., 2014a). Accordingly, for appropriate reasons related to the homogeneity of the comparison of data, they have been omitted.

As can be seen from Table 3 , the product sector that has contributed most to the production of waste (in quantitative terms) is identified with the cod. 009 which is fruit and vegetables, for a quantity of $208.138,88 \mathrm{~kg}$ and a loss of about $€ 378.182,32$, in 5 years.

The first results obtained have allowed us to concentrate and further refine the analysis of the identified sector, through careful monitoring it has been possible to isolate and subsequently classify the first 10 most significant products in terms of waste (Table 4).

Table 4 shows that the highest value, in terms of waste in respect to the quantity ordered, is given by the product "prepared salad (in bag)" which, as a productmix and ready for use, may not fully represent the eating habits of the population served as well as being characterized by a higher price than other products (Arshad and Abdel Hameed, 2013).

\subsection{Analysis of the two Most Wasted Fruit and Vegetables and Possible Intervention Strategies}

From the analysis of the data collected during the survey period followed by its processing, it was then possible to make some assessments that have allowed us to make a further distinction between food wastage (loss + waste) and simple waste and to propose, based on these assumptions, the policies to be adopted for the distribution/marketing and outline the possible outcomes in terms of reducing the amount waste (Mirabella et al., 2014). 
Table 1. Definition of context analysis

\begin{tabular}{|c|c|c|c|c|c|c|c|c|}
\hline \multicolumn{2}{|c|}{ Municipality } & $\begin{array}{l}\mathrm{N}^{\circ} \text { of outlets } \\
\text { analyzed }\end{array}$ & $\begin{array}{l}\text { Population } \\
\text { (istat data) }\end{array}$ & $\begin{array}{l}\text { Customer population } \\
\text { at the point of sale } \\
\text { (on a yearly average) }\end{array}$ & Hills & Coastal & \multicolumn{2}{|c|}{$\begin{array}{l}\text { Economic inclination } \\
\text { Agriculture tourism }\end{array}$} \\
\hline \multicolumn{2}{|c|}{ Barcellona pozzo di gotto } & 1 & 41.585 & 329.733 & $X$ & $X$ & Low & Low \\
\hline \multicolumn{2}{|c|}{ Capo d'orlando } & 1 & 13.307 & 141.665 & & $\mathrm{X}$ & Low & Medium \\
\hline \multirow[t]{5}{*}{ Messina } & ME 1 & & & 286.973 & & & & \\
\hline & ME 2 & & & 31.547 & & & & \\
\hline & ME 3 & 5 & 243.262 & 219.572 & $\mathrm{X}$ & $\mathrm{X}$ & Low & Medium \\
\hline & ME 4 & & & 105.061 & & & & \\
\hline & ME 5 & & & 488.567 & & & & \\
\hline Milazzo & & 1 & 31.882 & 313.125 & & $X$ & Medium & High \\
\hline \multicolumn{2}{|c|}{ Monforte san giorgio } & 1 & 2.831 & 132.989 & $X$ & & Low & Low \\
\hline \multicolumn{2}{|c|}{ San filippo del mela } & 1 & 7.245 & 58.023 & $X$ & & Low & Low \\
\hline \multicolumn{2}{|l|}{ Patti } & 1 & 13.420 & 147.098 & $\mathrm{X}$ & $X$ & Low & Medium \\
\hline \multicolumn{2}{|c|}{ S. Teresa di riva } & 1 & 9.438 & 236.716 & & $\mathrm{X}$ & Medium & Low \\
\hline \multicolumn{2}{|c|}{ Villafranca tirrena } & 1 & 8.648 & 353.680 & & $X$ & Low & Medium \\
\hline \multicolumn{2}{|l|}{ Total } & 13 & 371.618 & 2.844 .749 & - & - & - & - \\
\hline
\end{tabular}

Table 2. Incidence of waste on turnover (2009 to 2013)

\begin{tabular}{llllll}
\hline Years & 2009 & 2010 & 2011 & 2012 & 2013 \\
\hline Point of sale & Total & Total & Total & Total & Total \\
Economic loss due to rejection & $€ 184.685,96$ & $€ 162.478,61$ & $€ 168.903,70$ & $€ 189.674,60$ & $€ 286.895,70$ \\
Affect $\%$ & $0,36 \%$ & $0,31 \%$ & $0,32 \%$ & $0,34 \%$ & $0,52 \%$ \\
\hline
\end{tabular}

Table 3. Sectors that contributed the most to the waste (sorting by quantity), 2009-2013

\begin{tabular}{llll}
\hline $\mathrm{N}^{\circ}$ & Sector & Waste & \\
\hline$(\mathrm{kg})$ & Value of loss in economic terms (estimated) & \\
1 & Sector 009-fruit and vegetables & $208.138,88$ & $€ 378.182,32$ \\
2 & Sector 008-butcher & $76.638,40$ & $€ 515.101,83$ \\
3 & Sector 006-poultry & $65.072,72$ & $€ 368.163,88$ \\
4 & Sector 003-delicatessen & $50.680,83$ & $€ 812.347,44$ \\
& Total & $400.530,83$ & $€ 2.073 .795,47$ \\
\hline
\end{tabular}

Table 4. Products Top 10 in terms of food waste

\begin{tabular}{|c|c|c|c|c|c|c|}
\hline Product & Waste $(\mathrm{kg})$ & $\begin{array}{l}\text { Value of loss in } \\
\text { economic terms } \\
\text { (estimated) }\end{array}$ & $\begin{array}{l}\text { Quantity ordered } \\
(\mathrm{kg}) \text { (average } \\
5 \text { years) } \\
\end{array}$ & $\begin{array}{l}\text { Value of quantity } \\
\text { ordered (estimated) }\end{array}$ & $\begin{array}{l}\text { Affect } \\
\text { Waste/quantitative } \\
\text { ordered }(\%) \\
\end{array}$ & $\begin{array}{l}\text { Average waste } \\
\text { per capita for } \\
\text { all the outlets }\end{array}$ \\
\hline Fennel & $24.467,00$ & $€ 19.691,78$ & $199.786,727$ & $€ 161.196,533$ & 12,2 & 0,009 \\
\hline Tomato & $17.078,68$ & $€ 16.639,77$ & $168.109,918$ & $€ 158.061,027$ & 10,2 & 0,006 \\
\hline White cauliflower & $12.090,10$ & $€ 10.549,43$ & $106.270,892$ & $€ 112.568,616$ & 11,4 & 0,004 \\
\hline Blue eggplant extra & $8.302,02$ & $€ 7.463,53$ & $193.046,028$ & $€ 178.697,469$ & 4,3 & 0,003 \\
\hline Green salad & $7.983,11$ & $€ 6.868,01$ & $63.245,498$ & $€ 59.654,565$ & 12,6 & 0,003 \\
\hline Lettuce iceberg (in plastic bag) & $7.883,21$ & $€ 7.507,47$ & $26.873,000$ & $€ 41.746,895$ & 29,3 & 0,003 \\
\hline White zucchini & $7.832,20$ & $€ 8.405,49$ & $118.412,197$ & $€ 130.060,648$ & 6,6 & 0,003 \\
\hline Lettuce salad & $5.418,21$ & $€ 6.311,26$ & $116.933,549$ & $€ 142.740,613$ & 4,6 & 0,002 \\
\hline Fresh spinach (in bag) & $5.298,21$ & $€ 8.742,80$ & $94.448,000$ & $€ 108.425,822$ & 5,6 & 0,002 \\
\hline Prepared salad (in bag) & $3.877,34$ & $€ 6.316,20$ & $8.668,000$ & $€ 17.469,959$ & 44,7 & 0,001 \\
\hline Total & $100.230,08$ & $€ 98.495,74$ & $1.095 .793,81$ & $€ 1.110 .622,15$ & 9,1 & 0,035 \\
\hline
\end{tabular}


To this end, calculations have been carried out based on the two products (Fennel and Tomato) most wasted and representative of the two categories in question (Food Wastage and Food Waste), with the necessary interpretations, as shown in the Table 5.

The study covered the two products and the period under review:

- The trend of wastage/waste in quantitative terms

- The seasonal nature of the wastage/waste

- The performance of wastage/waste at point of sale

- The amount of waste per capita at point of sale

Regarding the first point, the comparison between the two products examined shows a decreasing trend of waste in the course of the 5 years examined, at least in the case of the first product, "fennel", wastage.

Conversely, the second product, tomato, shows an increasing trend (waste) (Iotti and Bonazzi, 2014).

The reduction is indicative of the fact that the LSC implements its internal policies aimed at the reduction of the unsold such as: Reduction of the selling price in the vicinity of the expiry date or in case of excessive ripening, as well as a rescheduling of orders (on a weekly basis) in proportion to the unsold in stock, even if, in the latter case, the quantity of annual orders, except in some cases, tends to maintain an increasing trend (Belekoukias et al., 2014) (Fig. 1).

The second point has allowed us to gather some feedback on the seasonality of wastage/waste in relation to the two products in question (Fig. 2).

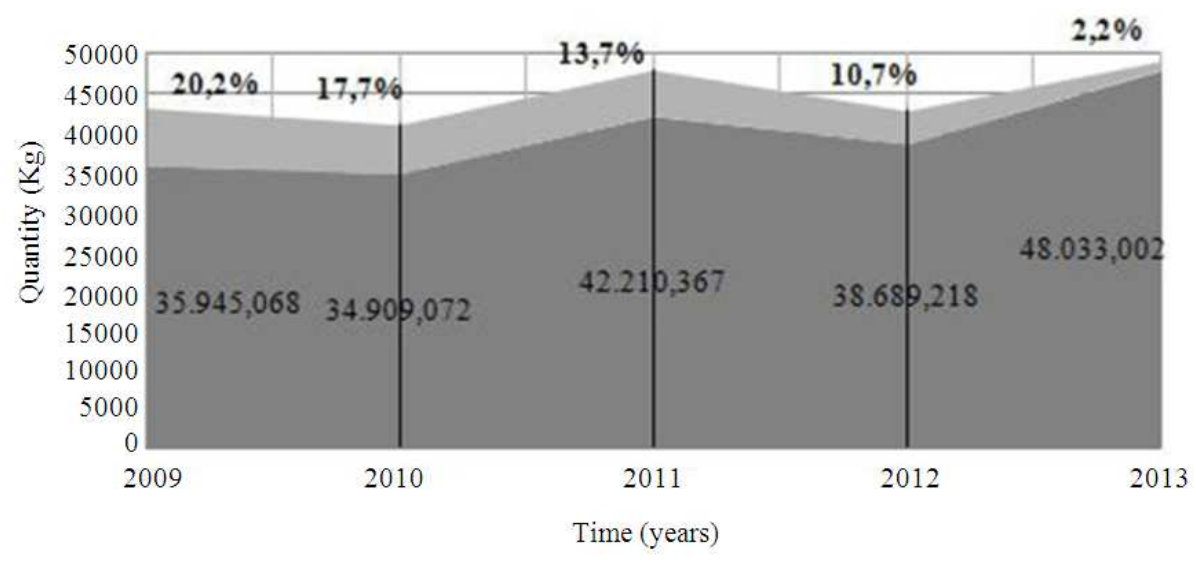

m Trend of wastage $\quad$ Quantity ordered

(a)

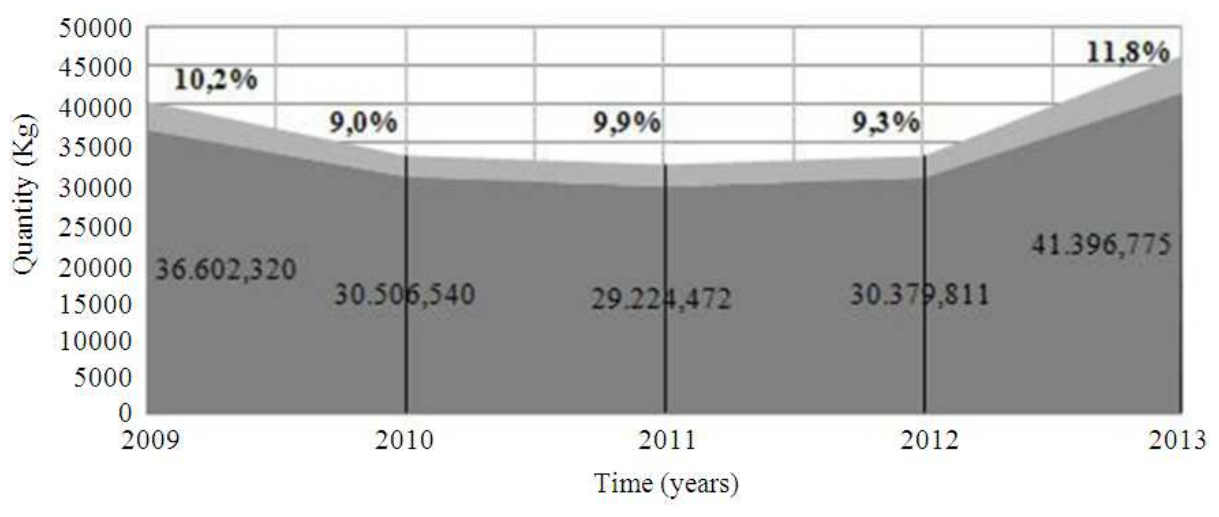

a Trend of waste $\quad$ Quantity ordered

(b)

Fig. 1. Trend of food wastage-Fennel (a)-and food waste-omato (b)-in respect of the quantity purchased, between the two products tested 
Maurizio Lanfranchi et al. / American Journal of Applied Sciences 11 (10): 1860-1874, 2014

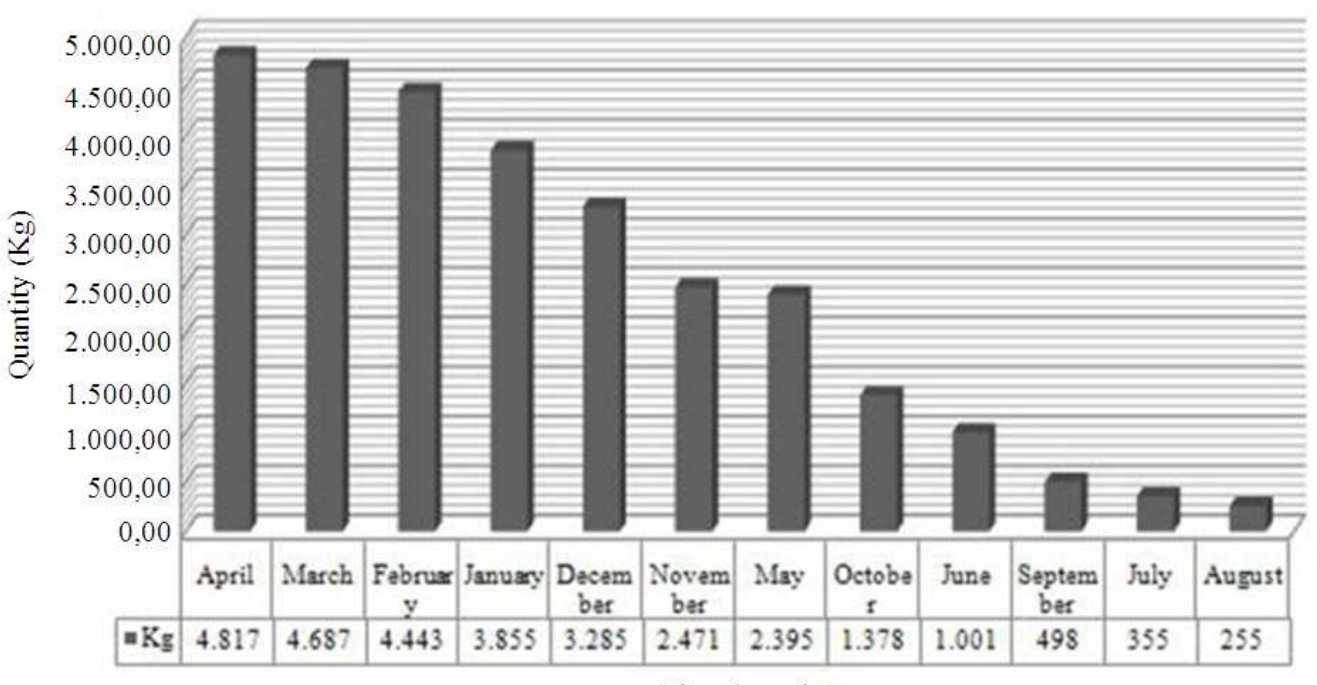

Time (months)

(a)



(b)

Fig. 2. Performance of the food wastage-Fennel (a)-and food waste-Tomato (b)-spread per month

The comparison made shows that while in the first case which is the first three/four months when there is a high enough quantity of wastage, while from December to August, the phenomenon tends to reduce significantly, to values of almost no significance. This might indicate that the product, in the months in which there is greater waste, is replaced by the local product which could be for personal consumption, but a later analysis (Fig. 3) tends to reject this consideration because the outlets which represent a higher incidence in the gap are characterized by low agricultural activity.

The second product "tomato", even if waste is lower than the previous product, registers, however, an almost constant trend (Fig. 2).

The last point deals with the extent of the treated wastage/waste for the 13 outlets analyzed. As is apparent from Fig. 3, the trends appear to not match in the two cases analyzed. 
Maurizio Lanfranchi et al. / American Journal of Applied Sciences 11 (10): 1860-1874, 2014

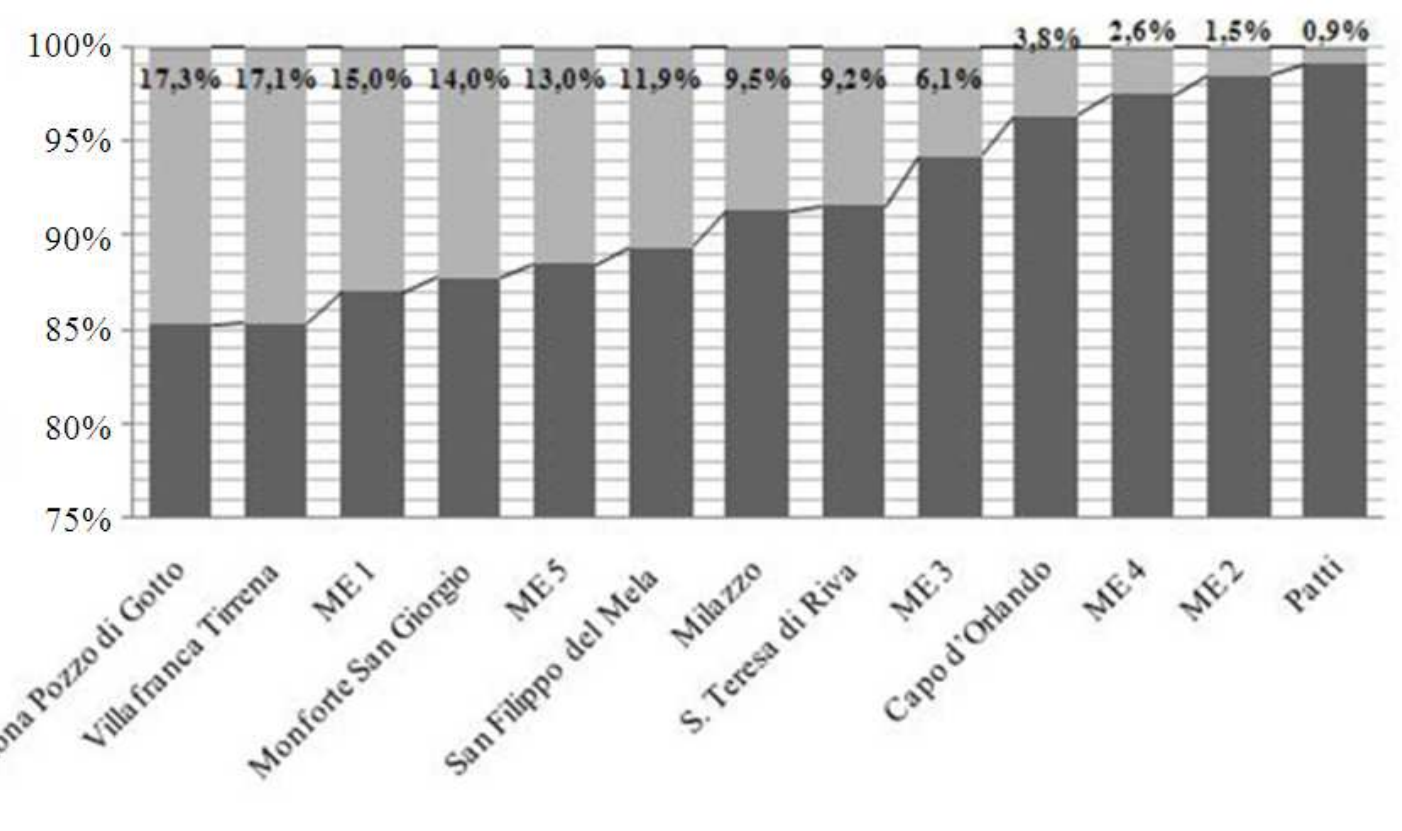

Euantity of wastage $\mathbf{m}$ Quantity purchased

(a)

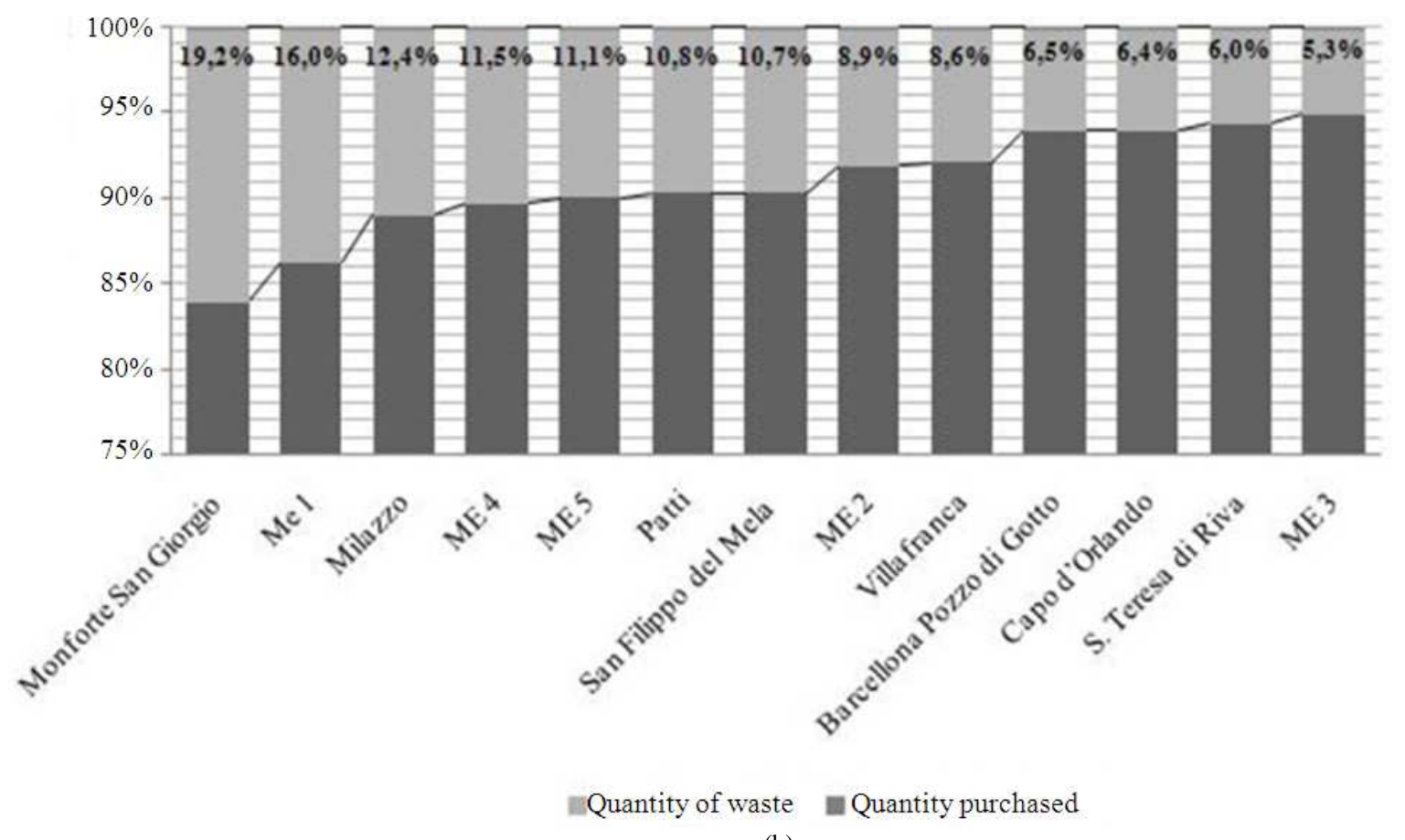

(b)

Fig. 3. Performance of the food wastage-Fennel (a)-and food waste-Tomato (b)-in relation to the quantity purchased, between the two products examined, for each point of sale 
Table 5. Examples of food rejection

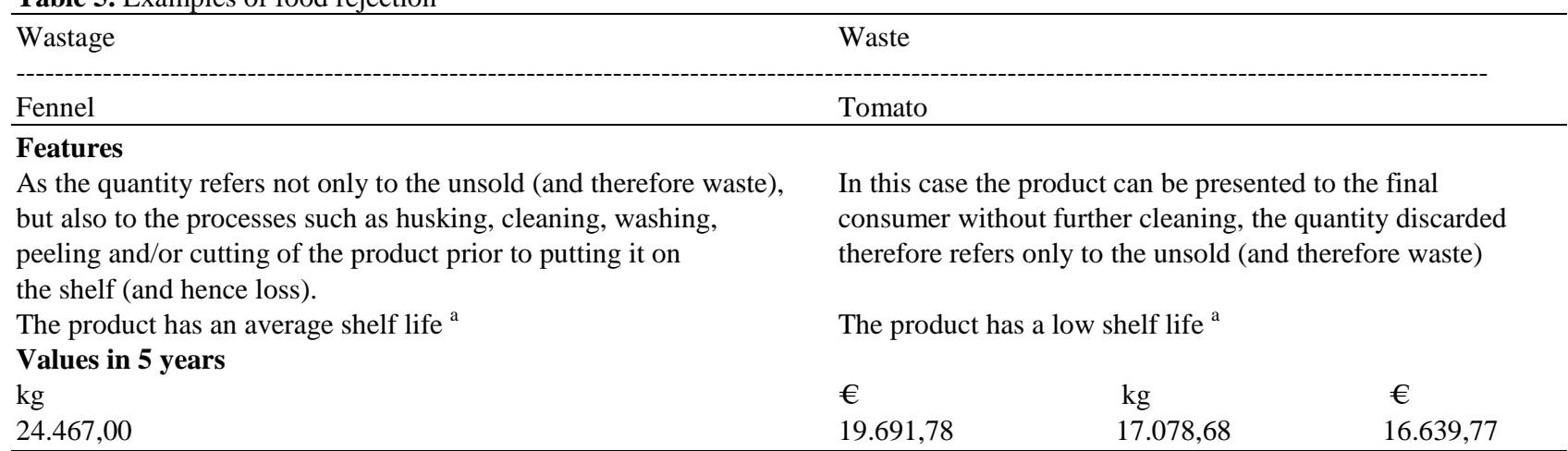

${ }^{a}$ the following convention on the average shelf life of foods is max 5 days shelf life low; max 10 days average shelf life; max 15 days high shelf life

In fact, the stores where the wastage is accounted for mainly by the product "fennel" tend to not coincide, except in one case (ME 1), with the outlets where the food waste is the "tomato".

This would suggest that the difference is not attributable to an erroneous product management or a malfunction of cold storage and then to improper storage inside the outlets analyzed, but only to the buying habits of consumers.

Furthermore, in the first case (the product "fennel"), except for the first three values that meet or exceed $15 \%$ and which related to, in the first two points of sale, modest territorial size and in the third a big selling point in the centre/north of the city, where it can be noted that the waste tends to progressively reduce to almost insignificant values between 3 and $0.9 \%$ in respect to the supply.

In the second case, i.e., the waste, however, except for the first two values which are above $15 \%$, including one store located in a city of modest size and the other store located in the centre/north of the city, the values rang between 12 and $5 \%$.

The data indicative of the effects of the economic situation on the availability of income and, therefore, expense of citizens.

A further examination has allowed us to assess the value of the gap per capita, for both products and points of sale highlighting the values shown in figure (Fig. 4).

The graphs illustrated that the only point in common between the two products is to be found in the value of waste per capita which reaches its peak for the customers that buy from the same point of sale, similar considerations are not, however, be found in other cases.

\subsection{The Impact of Food Waste in the Area of Analysis}

The research team conducted an estimate of the economic and environmental impact due to the waste in the area of the analysis (Lanfranchi et al., 2014b).

The methodology draws on previous studies, with the assumption that it is desirable to calculate the Willingness to Pay (WTP) on behalf of the community, of the residents in the municipalities in which the 13 outlets analyzed, a price to preserve the planet.

The economic impact of waste is determined by calculating the WTP, i.e., the willingness on behalf of the population to pay, in addition to the market price, a surplus price to protect the environment. Using the above method, we were able to quantify the willingness to pay for the $\mathrm{CO}_{2}$ quota system established by the EU to regulate the emissions of greenhouse gases.

In this way we can estimate both the impact of waste on the environment as well as the economic impact. To calculate the environmental impact we refer to the amount of food wasted detected in the stores analyzed in the survey period (2009-2013).

Applying the indicators of carbon footprint and the relative conversion tables established by the EU and invoking the study perfected by Segrè and Falasconi (2011), we can calculate the environmental impact of the waste of only the fruit and vegetables sector at the distribution stage (Segrè and Falasconi, 2011), (Table 6).

The estimated values are worrying as they are to be interpreted taking into account that the findings relate to the 13 stores and the estimate refers only to fruit and vegetables.

Table 7 shows the estimate of the economic and environmental impact of food waste at the points analyzed. 


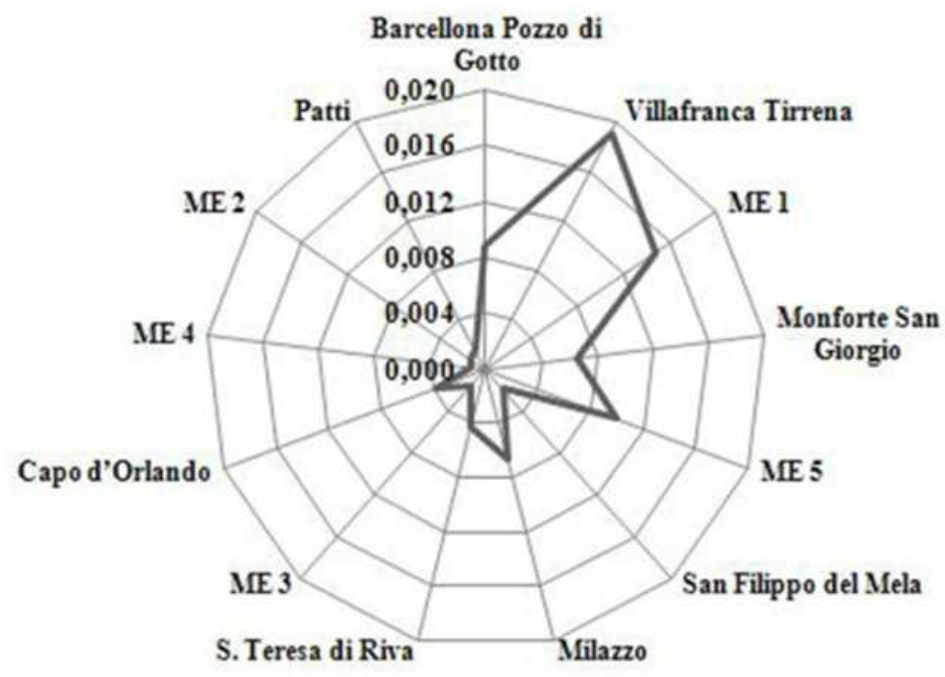

W-Wastage per capita (Fenuel kg)

(a)

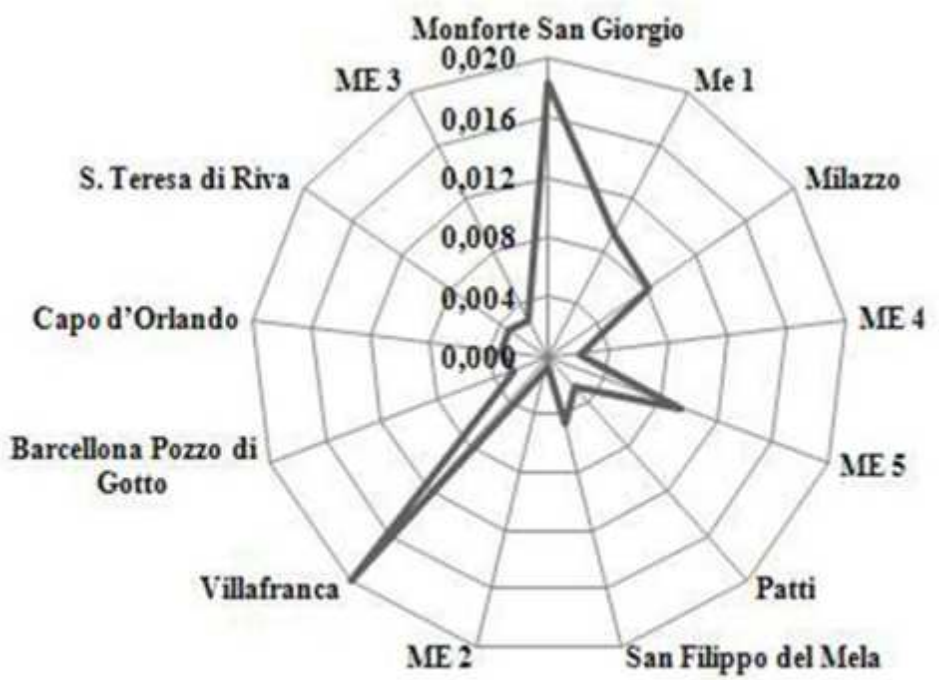

Waste per capita (Tomato)

(b)

Fig. 4. Value of food wastage-fennel (a)-and food waste-tomato (b)-per capita, per outlet

Table 6. Vegetables wasted and environmental impact

\begin{tabular}{llll} 
& Carbon footprint $\left(\mathrm{kg} \mathrm{CO}_{2}\right)$ & Water footprint $\left(\mathrm{m}^{3}\right.$ of water $)$ & Ecological footprint $\left(\right.$ total $\left.\mathrm{m}^{2}\right)$ \\
\hline per $\mathrm{kg}$ & 0,080 & 0,7 & 3,7 \\
Total & 16.651 & 145.697 & 770.113 \\
\hline
\end{tabular}

Source: Our elaboration 
Table 7. Socio-economic impact of food waste in the 13 outlets analyzed (2009-2013)

\begin{tabular}{llllll}
\hline Category & $\begin{array}{l}\text { Quantity of } \\
\text { waste in } \mathrm{kg}\end{array}$ & $\begin{array}{l}\text { Value lost due } \\
\text { to waste } €\end{array}$ & Ton. of $\mathrm{CO}_{2}$ & $\begin{array}{l}\text { Quota value } € \\
\text { (estimate 0,02 } € / \mathrm{kg} \text { ) }\end{array}$ & $\begin{array}{l}\text { Economic impact } \\
\text { of waste }\end{array}$ \\
\hline Sector 09-fruit and vegetables & $208.138,88$ & $€ 378.182,32$ & 16,65 & 333,02 & $€ 378.515,34$ \\
Sector 008-butcher & $76.638,40$ & $€ 515.101,83$ & $1.226,21$ & $24.524,28$ & $€ 539.626,12$ \\
Sector 006-poultry & $65.072,72$ & $€ 368.163,88$ & 104,12 & $2.082,32$ & $€ 370.246,21$ \\
Sector 003-delicatessen & $50.680,83$ & $€ 812.347,44$ & 255,94 & $5.118,76$ & $€ 817.466,20$ \\
Total & $400.530,83$ & $€ 2.073 .795,47$ & $1.602,92$ & $32.058,40$ & $€ 2.105 .853,87$ \\
\hline
\end{tabular}

The value of the $\mathrm{CO}_{2}$ emissions is a conservative average value of 20 Euros per ton. as can be seen from Table 7, in the area investigated food waste takes on a negative economic value equal to $€ 2.105 .853,87$ giving an average annual waste of $€ 421.170,77$ (Grillone et al., 2012).

\section{RESULTS}

The findings and considerations and the subsequent estimates are the results of the research conducted by the authors. On the basis of the assessments made, by reviewing the literature on the subject and by reviewing the international literature, all led to a lack of data on the production of food waste and a significant change in the estimates, Parfitt et al. (2010) emphasize that "Food waste occurs at different points in the supply chain, although it is most readily defined at the retail and consumer stages, where outputs of the agricultural system are self-evidently "food" for human consumption" (Parfitt et al., 2010). In addition, some field studies have shown that, in the context of retail, approximately $25-30 \%$ of fruit and vegetables is discarded because of cosmetic defects, such as inadequate size or shape, holes or bruises (Stuart, 2009).

In this regard, in order to identify corrective actions aimed at reducing waste and on the basis of similar experiences undertaken at international level, it was thought to conduct, at LSC level, an anti-waste campaign aimed at the final consumer, including the application of an appropriate trade mark to be affixed to products having the same characteristics of:

- Highly perishable

- Close expiry date

- Aesthetic standards not perfect

Also in accordance with the provisions of the European Parliament Resolution of 19 December 2012 which asks to explain the nutritional value of agricultural products with imperfect forms, because it believes that the quality requirements imposed by
European or national legislation or international standards concerning the form and the size of fresh fruit and vegetables are the basis of unnecessary waste and in accordance with the European Regulation CE No 1221/2008 that regulates the standards of quality of fruit and vegetables and allows the sale of products that are less aesthetic.

The research group proposed to the 13 stores analyzed, as a strategy of intervention aimed at reducing waste, the adoption of an experimental antiwaste campaign, which will be the subject of further observations and further studies by the same research group, in order to assess the possibility of extending this strategy to the entire distribution channel (Lanfranchi et al., 2014c).

In this regard, the products, object of the campaign, are characterized by: Lower price than fresh produce, this would facilitate the consumption for families with low incomes and, therefore, low spending power, since the European Parliament Resolution of 19 December 2012, calls on all Member States to allow retailers to lower prices of fresh produce to below the cost of production, if close to the expiry date, to allow consumers with low disposable income, the opportunity to buy high-quality products at affordable prices.

To this end it proposes two different scenarios of estimates for the reduction of wastage (Fig. 5) and waste (Fig. 6), for both the products analyzed, in which a reduction of food waste of $13 \%$ in three years can be expected (value obtained in similar experiences in the field).

The trend (Linear Forecast Trendline-quantity) indicates the reduction achieved in respect to the growth data:

- 2012 (actual data + estimated figures) if a campaign aimed at reducing the waste in the form of a trade mark had been adapted

- 2013 growth figure, with no campaign/brand had been adapted, but only with the actions already taken by the LSC

- 2015 as a scenario (projections) to be expected in the next three years 


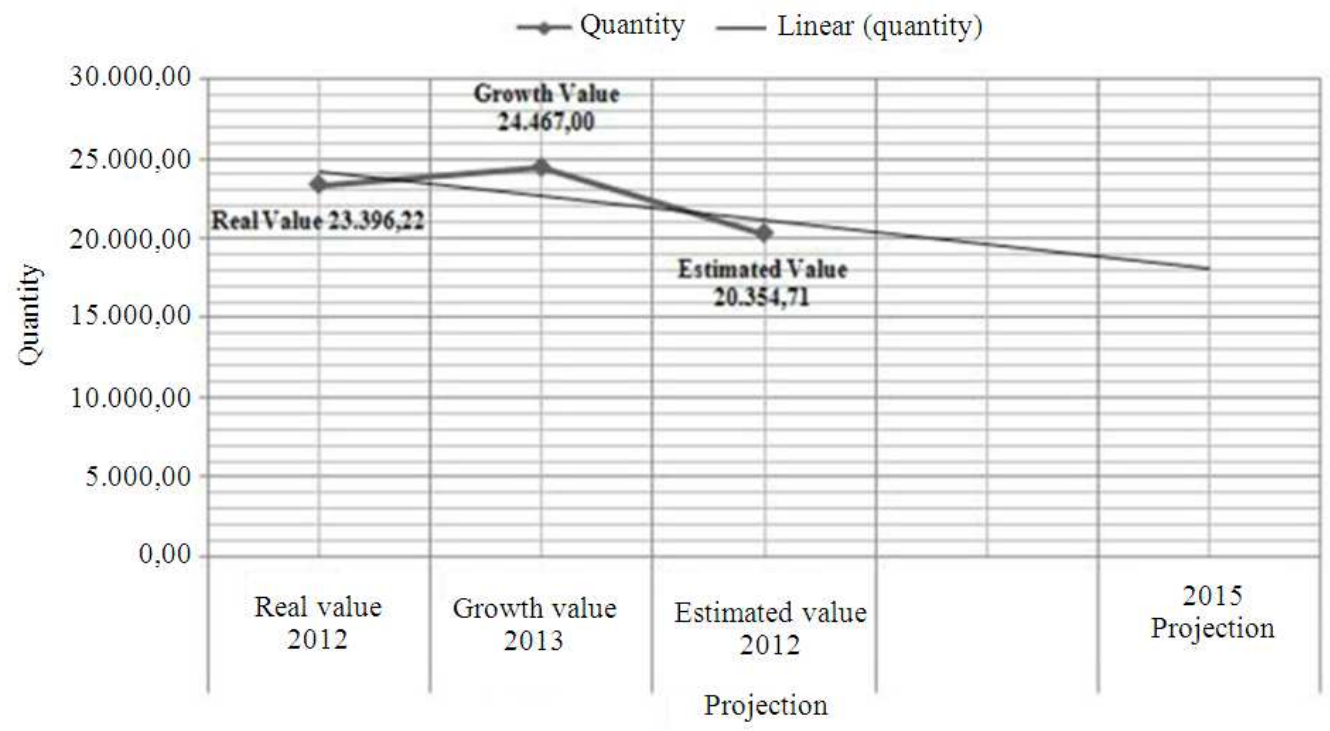

Fig. 5. Scenario of reducing food waste-campaign to reduce waste-results obtainable in three years (Fennel $\mathrm{kg}$ )

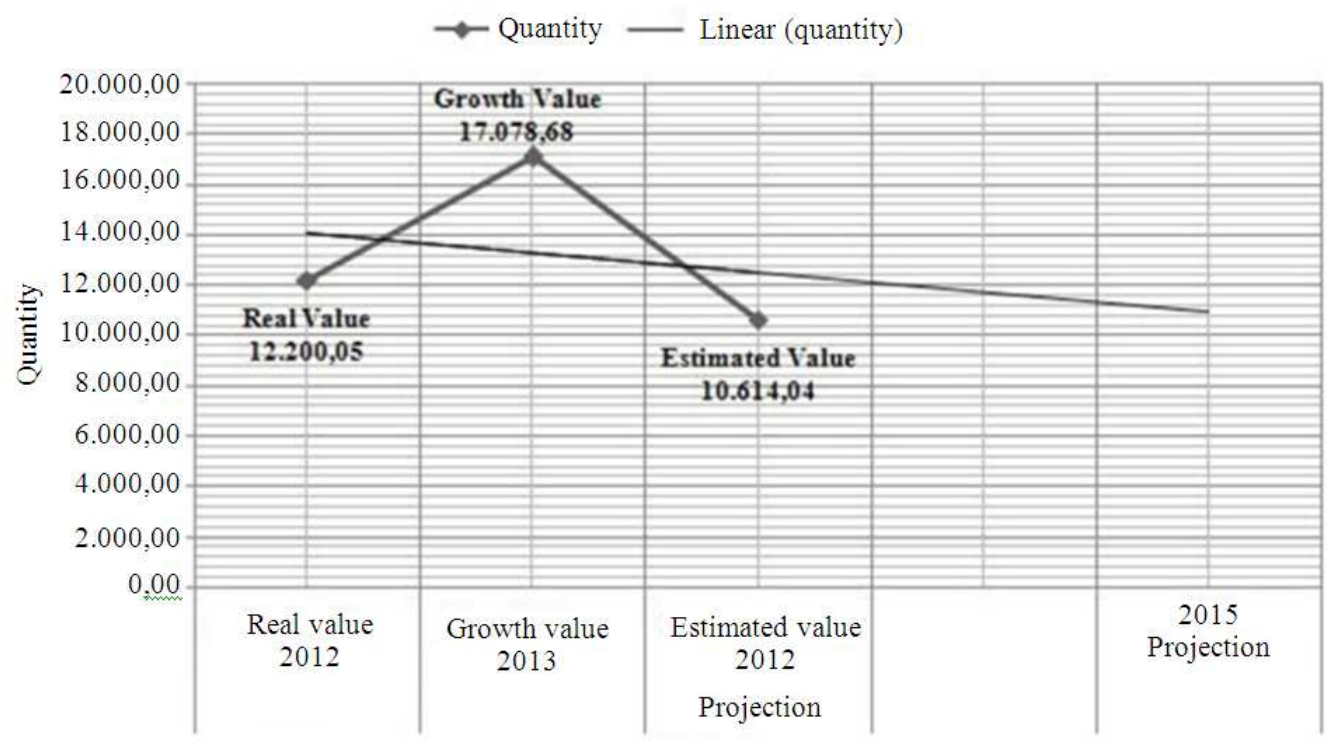

Fig. 6. Scenario of reducing food waste-campaign to reduce waste-results obtainable in three years (Tomato $\mathrm{kg}$ )

The results achieved allow to recover $13 \%$ of the actual trend of the gap in 2012, redeeming, in the case of the product "fennel", a quantity equal to $3.041,51$ $\mathrm{kg}$ for a resulting value (in terms of avoided loss) of $€$ 2.447,18; while in the case of the product "tomato" it would be equal to $1.586,01 \mathrm{~kg}$ for a value of $€$ 1.554,32.

That is, in total $€ 4.001,50$ of avoided loss.
Extending these considerations to ten products of the fruit and vegetable sector that recorded in 2012, a figure of actual waste equal to $86.330,40 \mathrm{~kg}$ with a given growth in 2013 of $100.230,08 \mathrm{~kg}$ thus bringing the level of waste (as showed-Fig 5 and $\mathbf{6}$-per the estimated value to 2012 , or contemplating a waste-campaign, in three years) to $75.107,45 \mathrm{~kg}$ with a recovery value of approximately $€ 11.115,05$. 


\section{DISCUSSION}

The observations carried out, in the examined area and analyzed outlets, do not allow us to attribute the phenomenon of waste to any consideration regarding the agricultural vocation or tourism of the area or of the individual locations. This is because the comments referring to the seasonality of waste or its quantity in a store do not allow us to certify the existence of any correlation between waste and:

- Cultivation for personal consumption

- Inadequate storage systems/storage in the different outlets considered

- Increase of customers in the area of the outlets, especially in summer, for reasons related to tourism, typical seaside resorts or vice versa

- Reduction of customers in the area of the outlets located in the city centre, whose population generally spends the summer at the nearby seaside resorts

- Also thanks to the considerable proportion of customers served in proportion to the overall resident population

In addition the particular nature of the products examined, the first "fennel" essentially a winter product; the second "tomato", typically used in processes and poorly consumed as a raw product, as well as the lack of ability to differentiate, in both cases, the mode of use.

This suggests that the waste is substantially due to the buying behaviour of consumers and particularly the ability to pay (purchasing power or price of the product) (Agnese et al., 2008). Precisely for this purpose, a brand/campaign against waste can, in a sense, guide the choices of consumers towards being a more conscious consumer, with economic, social and environmental advantages or acting simultaneously on the three pillars of sustainability (Lanfranchi, 2010).

\section{CONCLUSION}

In this study the brand or campaign to reduce waste, took into account only the fruit and vegetable sector, to meet the needs related to a group of products that over the last 5 years has seen a quantity of waste to justify it's monitoring, but it can be applied to any product which, in the point of sale, together or separately presents the characteristics of: Close expiry, highly perishable aesthetic standards not perfect (e.g., dairy products, juices, meats, etc...), integrating it with descriptive information about the characteristics of the product (usage, health reasons, calories or consumption suggestions e.g., recipes, remembering as specified in the Resolution of the European Parliament "... to know and explain the nutritional value of agricultural products which have imperfect forms or size (so as to reduce waste products"), in this case and with reference to the sectors analyzed in this study (Fruit and Vegetables Butcher, Poultry, Delicatessen), would have avoided that, in $2009-2012,5.069,01 \mathrm{~kg}$ of food to be wasted and thus estimating a recovery of economic value of approximately $€ 269.593,41$.

In the final analysis and taking into account the typical theories of welfare economics, it is necessary to underline that to this data it is necessary to add a valuation based on the impact of waste "on the usefulness to the whole society".

Therefore, in this calculation, not only the price should be taken into account (in this case the purchase price and then the loss in purely economic terms), but to be considered also are the negative externalities produced, thus, adding to the price, the estimated availability of society to pay a price for the environmental impact (Sgroi et al., 2014b). Moreover, in the light of the fact that a significant portion of land is used in a less useful way (to produce food that is not consumed) compared to other alternative ways, it might be useful to assess the opportunity cost of agricultural land used to produce goods wasted, in calculating the economic impact.

\section{ACKNOWLEDGEMENT}

The research team thank Prof. Frank Rotondo for his professional translation.

\section{ADDITIONAL INFORMATION}

\subsection{Funding Information}

This study is a result of the project "Pon04_00364 Smart Cities and Communities and Social Innovation Axis II-Development of models for simplification of the food chain" coordinated by Maurizio Lanfranchi.

\subsection{Author's Contributions}

The work is the result of a full collaboration of the authors. However, Maurizio Lanfranchi, in addition to coordination and setting the study, the writing of the paragraphs $1.1 ; 2.1 ; 2.5$ and 5, Carlo Giannetto paragraphs 2; 2.2 and 4 and Angelina De Pascale paragraphs $1 ; 2.3$; and 3, while Lanfranchi, Giannetto and De Pascale wrote the paragraphs 2.4. 


\subsection{Ethics}

This article is original and contains unpublished materials. The corresponding author confirms that all of the other authors have read and approved the manuscript and no ethical issues involved.

\section{REFERENCES}

Agnese, C., F. D'Asaro, G. Grillone and A. Drago, 2008. Comparison of temperature data collected in urban and agricultural areas surrounding. Italian $\mathrm{J}$. Agrometeorol., 13: 48-49.

Arshad, F.M. and A.A. Abdel Hameed, 2013. Price transmission in selected Malaysian fruits markets. Am. J. Applied Sci., 11: 347-355. DOI: 10.3844/ajassp.2014.347.355

Belekoukias, I., J.A. Garza-Reyes and V. Kumar, 2014. The impact of lean methods and tools on the operational performance of manufacturing organisations. Int. J. Product. Res., 52: 5346-5366. DOI: $10.1080 / 00207543.2014 .903348$

Bernstad, A., 2014. Household food waste separation behavior and the importance of convenience. Waste Manage., 34: 1317-1323. DOI: 10.1016/j.wasman.2014.03.013

Crescimanno, M., A. Galati and T. Bal, 2014. The role of the economic crisis on the competitiveness of the agri-food sector in the main Mediterranean countries. Agric. Econ. Czech Republic, 60: 49-64.

D'Amico, M., G. Di Vita and S. Bracco, 2014. Direct sale of agro-food product: The case of wine in Italy. Quality-Access Success, 15: 247-253.

Di Trapani, A.M., R. Squatrito, M. Foderà, R. Testa and S. Tudisca et al., 2014. Payment for environmental services for the sustainable development of the territory. Am. J. Environ. Sci., 10: 480-488. DOI: 10.3844/ajessp.2014.480.488

D'Silva, J.L., H.A.M. Shaffril, J. Uli and B.A. Samah, 2010. Socio-demography factors that influence youth attitude towards contract farming. Am. J. Applied Sci., 7: 603-608. DOI: 10.3844/ajassp.2010.603.608

Er, A.C., A.R.M. Nor and K. Rostam, 2011. Palm oil milling wastes and sustainable development. Am. J. Applied Sci., 8: 436-440. DOI: 10.3844/ajassp.2011.436.440

Fiore, S., M.C. Zanetti and B. Ruffino, 2008. Waste characterization in steel casting and recycling opportunities in Europe. Am. J. Applied Sci., 5: 512518. DOI: $10.3844 /$ ajassp.2008.512.518
Garnsworthy, P.C., 2012. Sustainable intensive farming systems. EAAP Sci. Series, 131: 139-144.

Giuseppe, A., E. Mario and M. Cinzia, 2014. Economic benefits from food recovery at the retail stage: An application to Italian food chains. Waste Manage., 34: 1306-1316. DOI: 10.1016/j.wasman.2014.02.018

Graham-Rowe, E., D.C. Jessop and P. Sparks, 2014. Identifying motivations and barriers to minimising household food waste. Resources, Conservat. Recycl., 84: 15-23. DOI: 10.1016/j.resconrec.2013.12.005

Grillone, G., C. Agnese and F. D'Asaro, 2012. Estimation of daily solar radiation from measured air temperature extremes in the Mid-Mediterranean area. J. Irrigat. Drainage Eng., 138: 939-947. DOI: 10.1061/(ASCE)IR.1943-4774.0000480

Iotti, M. and G. Bonazzi, 2014. Tomato processing firms management: A comparative application of economic and financial analyses. Am. J. Applied Sci., 11 : 1135-1151. DOI: 10.3844/ajassp.2014.1135.1151

Kim, Y.D., S. Yoon and H.G. Kim, 2014. An economic perspective and policy implication for social enterprise. Am. J. Applied Sci., 11: 406-413. DOI: 10.3844/ajassp.2014.406.413

Lanfranchi, M., 2010. Sustainable technology as an instrument of the enviromental policy for the attainment of a level of socially acceptable pollution. World Futures: J. General Evolut., 66: 449-454. DOI: 10.1080/02604020903423543

Lanfranchi, M., 2012. Economic analysis on the enhancement of citrus waste for energy production. J. Essential Oil Res., 24: 583-591. DOI: 10.1080/10412905.2012.739788

Lanfranchi, M., C. Giannetto and A. De Pascale, 2014a. Nature based tourism: Natural balance, impacts and management. Quality-Access Success, 15: 224-229.

Lanfranchi, M., C. Giannetto, A. Zirilli and A. Alibrandi, 2014b. Analysis of the demand of wine in Sicily through ordinal logistic regression model. QualityAccess Success, 15: 87-90.

Lanfranchi, M., C. Giannetto and A. Zirilli, 2014c. Analysis of demand determinants of high quality food products through the application of the cumulative proportional odds model. Applied Math. Sci., 8: 3297-3305.

Lanfranchi, M. and C. Giannetto, 2014. Sustainable development in rural areas: The new model of social farming. Quality-Access Success, 15: 219-223. 
Levis, J.W., M.A. Barlaz, N.J. Themelis and P. Ulloa, 2010. Assessment of the state of food waste treatment in the United States and Canada. Waste Manage., 30: 1486-1494. DOI: 10.1016/j.wasman.2010.01.031

Lo, M.C., 2009. Economic ordering quantity model with lead time reduction and backorder price discount for stochastic demand. Am. J. Applied Sci., 6: 387-392. DOI: 10.3844/ajassp.2009.387.392

Mahdei, K.N., S.M. Hosseini, M. Aazami and H. Saadi, 2010. Administrative feasibility of monitoring mechanisms implementation for sustainable agriculture. Am. J. Applied Sci., 7: 208-213. DOI: 10.3844/ajassp.2010.208.213

Mirabella, N., V. Castellani and S. Sala, 2014. Current options for the valorization of food manufacturing waste: A review. J. Cleaner Product., 65: 28-41. DOI: $10.1016 /$ j.jclepro.2013.10.051

Morley, A., J. McEntee and T. Marsden, 2014. Food futures: Framing the crisis. Sustainable Food Syst. Build. Paradigm.

Nahman, A. and W. de Lange, 2013. Costs of food waste along the value chain: Evidence from South Africa. Waste Manage., 33: 2493-2500. DOI: 10.1016/j.wasman.2013.07.012

Papargyropoulou, E., R. Lozano, J.K. Steinberger, N. Wright and Z.B. Ujang, 2014. The food waste hierarchy as a framework for the management of food surplus and food waste. J. Cleaner Product., 76: 106-115. DOI: 10.1016/j.jclepro.2014.04.020

Parfitt, J., M. Barthel and S. Macnaughton, 2010. Food waste within food supply chains: Quantification and potential for change to 2050. Philosophical Trans. Royal Society B., 365: 3065-3081. DOI: 10.1098/rstb.2010.0126

Pradhan, P., M.K.B. Lüdeke, D.E. Reusser and J.P. Kropp, 2014. Food self-sufficiency across scales: How local can we go. Environ. Sci. Technol., 48: 9463-9470. DOI: 10.1021/es5005939
Rentizelas, A.A., A.I. Tolis and I.P. Tatsiopoulos, 2014. Combined municipal solid waste and biomass system optimization for district energy applications. Waste Manage., 34: 36-48. DOI: 10.1016/j.wasman.2013.09.026

Segrè, L.F. and L. Falasconi, 2011. Il libro nero dello spreco in Italia: Il cibo, Edizioni Ambiente.

Sgroi, F., A.M. Di Trapani, R. Testa and S. Tudisca, 2014a. Economic sustainability of early potato production in the Mediterranean area. Am. J. Applied Sci., 11: 1598-1603. DOI: 10.3844/ajassp.2014.1598.1603

Sgroi F., A.M. Di Trapani, T. Testa and S. Tudisca, 2014b. Strategy to increase the farm competitiveness. Am. J. Agric. Biological Sci., 9: 394-400. DOI: 10.3844/ajabssp.2014.394.400

Stuart, T., 2009. Waste, uncovering the global food scandal. London, UK: Penguin.

Sulaiman, A.H., J. Othman, H.H. Hamsan, B.A. Samah and J.L. D'Silva, 2012. Community development and its influence on community policing. Am. J. Applied Sci., 9: 968-973. DOI: 10.3844/ajassp.2012.968.973

Taleizadeh, A.A., S.T.A. Niaki and M.B. Aryaneznad, 2009. Multi-product multi-constraint inventory control systems with stochastic replenishment and discount under fuzzy purchasing price and holding costs. Am. J. Applied Sci., 6: 1-12. DOI: 10.3844/ajassp.2009.1.12

Testa, R., A.M. Di Trapani, F. Sgroi and S. Tudisca, 2014. Economic analysis of process innovations in the management of olive farms. Am. J. Applied Sci., 11: 1486-1491. DOI: 10.3844/ajassp.2014.1486.1491

Tudisca, S., A.M. Di Trapani, F. Sgroi and R. Testa, 2013. The cost advantage of sicilian wine farms. Am. J. Applied Sci., 10: 1529-1536. DOI: 10.3844/ajassp.2013.1529.1536 